East African Medical Journal Vol. 87 No. 3 March 2010

OPTIMISATION OF PATIENT PROTECTION AND IMAGE QUALITY IN DIAGNOSTIC RADIOLOGY

G. K. Korir, BSc, MSc, PhD (Rad. Sci.), Graduate Student, Department of Physics and Applied Physics, University of Massachusetts Lowell, One University Ave. Lowell, MA 01854, USA, J. S. Wambani, MBChB, MMed (Rad.), MMed (Paed. Rad.), Chief Radiologist, Department of Radiology, Kenyatta National Hospital, P. O. Box 20723 - 00202, Nairobi, Kenya and B. O. Ochieng, BSc, MSc (Nucl. Med.), Medical Physicist, Department of Radiation Oncology, Aga Khan University Hospital Nairobi, P. O. Box 30270 - 00100, Nairobi, Kenya

Request for reprints: Dr. J. S. Wambani, Department of Radiology, Kenyatta National Hospital, P. O. Box 20723 - 00202 , Nairobi, Kenya

\title{
OPTIMISATION OF PATIENT PROTECTION AND IMAGE QUALITY IN DIAGNOSTIC RADIOLOGY
}

\author{
G.K. KORIR, J. S. WAMBANI and B.O. OCHIENG
}

\begin{abstract}
Objective: To determine the examination frequencies, quality of radiographic images and the entrance surface dose (ESD) in patients undergoing general radiographic examinations.

Design: Prospective study on the device performance, film reject rate, patient dose, and image quality during the use of standard and fast speed film screen combination. Setting: Radiology Department of Kenyatta National Hospital, a referral, teaching and research hospital in Kenya.

Subjects: A total of 837 adult and 229 paediatric patients undergoing diagnostic examinations were assessed for patient dose and image quality.

Interventions: The $\mathrm{X}$-ray tube output measurements and $\mathrm{X}$-ray exposure parameters were determined. The patients ESD on standard 200 and fast 400 speed film screen combination was determined. The radiographic image quality was assessed.

Main outcome measures: The findings were compared with the international diagnostic reference levels (DRL's) for determination of dose optimisation in diagnostic radiography.

Results: The relative frequency of examination was $80 \%$ and $20 \%$ for adults and paediatric patients respectively. The image quality improvement by $13 \%$ was achieved and patient dose reduction range of $31 \%$ to $77 \%$.

Conclusions: The patient dose reduction and image quality was achieved through a quantitative quality control $(\mathrm{QC})$ assessment of processes involved in producing radiographs. The study leads to the introduction of the concept of plan- do-check-act on QC results and optimise with a view of patient dose reduction. The department appreciated the value of a quality assurance (QA) programme and continues to collect data for establishment of DRL's.
\end{abstract}

\section{INTRODUCTION}

The developed countries recognised the risks of ionizing radiation and developed $\mathrm{QC}$ programmes to assess doses from radiological examinations. Through the IAEA regional technical cooperation Project RAF/09/033 framework, a standard questionnaire, image quality and patient dose levels were surveyed at the Kenyatta National Hospital.

Kenyatta National Hospital is a tertiary referral, teaching and research hospital located in the capital city of Nairobi. The hospital serves a large national population of approximately 36 million (1). The large population and the concentration of imaging professionals in the city has resulted in a large number of diagnostic radiology referrals. This extensive use of $X$-rays for medical diagnosis presents a large component of public exposure to ionizing radiation.

The majority of developing countries especially in Africa have X-ray machines that are old, poorly serviced or not maintained at all. The machines have no in built dosimeters and most departments lack current QC programmes and established epidemiological reference data.

Research has shown that in a population of normal age distribution, the possibility of fatal radiation induced cancer due to low dose is estimated at $6.2 \%$ per sievert and $0.2 \%$ per sievert for hereditary effects (2). The establishment of diagnostic image 
quality criteria is an essential step in the optimisation of patient doses in general diagnostic radiography. The "European Guidelines on Quality Criteria for Diagnostic Radiographic Images" provides details on the diagnostic requirements for normal basic radiographs specifying anatomical image criteria. Examples of good radiographic technique for diagnostic requirements and criteria for patient dose are given (3). The comparison of doses with DRL's helps in the optimization process.

Kenyatta National Hospital promotes international health strategy for establishing, developing, and consolidating adequate systems for the radiological protection of patients, medical exposure control, and modular approach in QA for optimizing patient dose and image quality $(4,5)$. The aim of the study was to survey the quality of the radiographic images, the ESD to patients exposed to radiographic examinations, optimisation of patient dose and comparison with international diagnostic reference levels.

\section{MATERIALS AND METHODS}

This study involved the analysis of examination frequencies and film rejects, measurement of patient dose, performance testing of the X-ray machines, and assessment of image quality when using two different screen film combination.

a) Examination frequencies: The relative frequency for radiographic examinations was derived from the mean values obtained from patient records of at least three months of the study period. Most of the adult patientexaminations (clinic, accident and emergency) were performed in designated room 1, while complex abdominal examinations were performed in designated room 2 . All the children examinations were performed in room designated 3 .

b) Film rejects: During the use of standard speed film and after the change to 400 speed film screen combination, film reject analysis was done over a period of one month for the three rooms mentioned above for performing general radiography. Rejected films were collected, counted and categorised according to the size, type and analysed by a senior experienced imaging technologist.

c) Quality control tests for the X-ray device: Two X-ray performance tests were done, first at the end of the use of 200 speed and second at the beginning of the use of 400 speed film screen combination. The QC tests were performed on each of the three X-ray machines (Philips, Netherlands installed in 1990). Thetests were performed using calibrated Radiation Measurement Inc QC equipment. The machines have both manual and automatic exposure control settings, Model RO 1230 Rotarix tubes and model Medio 50 CP three phase generators. The performance faults were corrected by the Philips servicing and maintenance engineers before the change of film/screen combination. The items tested include the following:
(i) $\mathrm{kVp}$ accuracy
(ii) Reproducibility of exposure
(iii) Timer accuracy
(iv) $\mathrm{mA}$ and exposure time linearity
(v) Radiation output
(vi) Light/radiation beam alignment
(vii) Focal spot size (mm) small/large
(viii) Half-value layer-HVL (mm AI)

An X-ray machine either 'Passed' or 'Failed' a particular QC test parameter based on the New South Wales Environment Protection Authority Methods and Standards (6).

d) Patient dose assessment: For each examination considered before and after the change of the film screen combination, an open thermoluminiscence dosimeters (TLD) (Erlangen, Germany) was strapped using tape into the central position of the beam on the patient's skin surface. The patient's body thickness, $\mathrm{kVp}, \mathrm{mA}$ and exposure time were recorded. Direct radiography was used for adult chest $\mathrm{AP}$ and for children less than fifteen years. The dose delivered to the TLD cards was read using a Harshaw 4500 TLD Reader (Erlangen, Germany) at the National Radiation Protection Laboratory located in the same hospital compound. A relative uncertainty of $10 \%$ was adopted for TLD measurements reported (7).

e) Image quality assessment: During the use of both screen film combinations, each radiograph obtained from each examination whose measurements were made or recorded was assessed for image quality compliance according to European Commission (EC) quality criteria (3) by experienced radiologists. A grading system of A, B or C was assigned for each radiograph. Grade Ameant accepted unconditionally (features detected and fully reproduced, details visible and clearly defined), B meant accepted with reservations (features just visible, details just visible but not clearly defined) and $C$ meant rejected (features invisible, details invisible and undefined). 


\section{RESULTS}

a) Examination frequency

Figure 1

Radiographic examinations considered before and after change of film screen combination

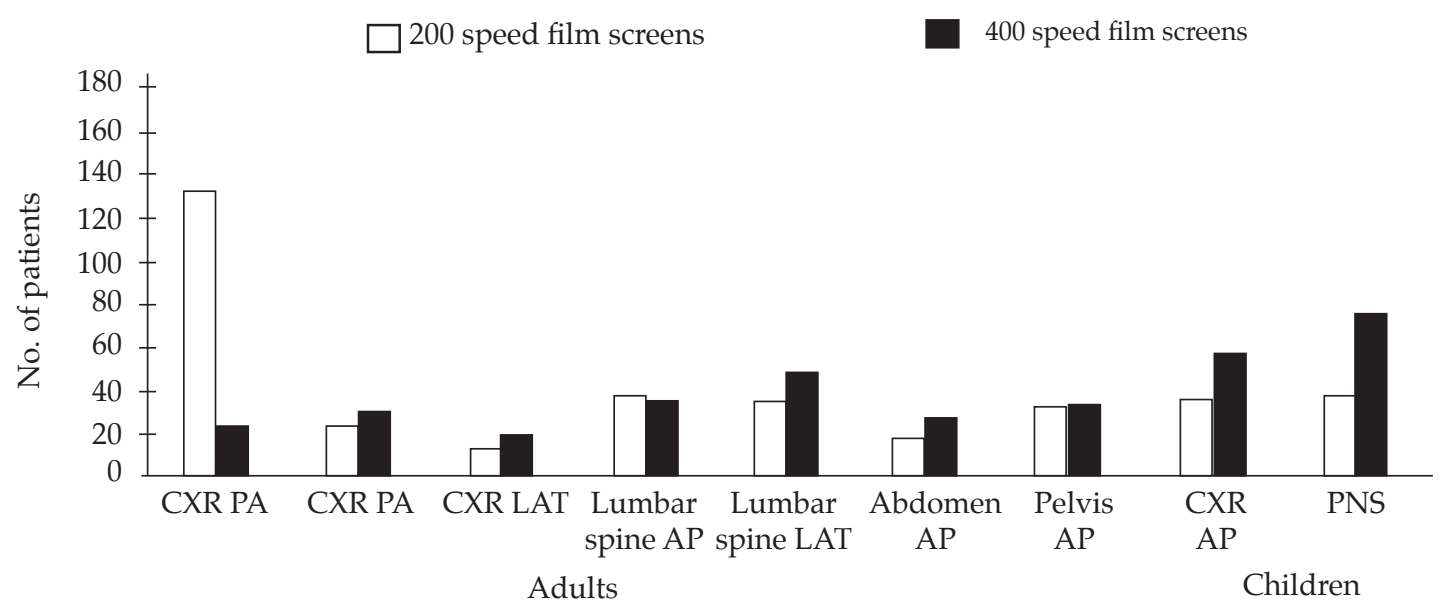

Type of examination

b) Rejects analysis

Figure 2

Relative frequencies of rejects before and after change of film screens

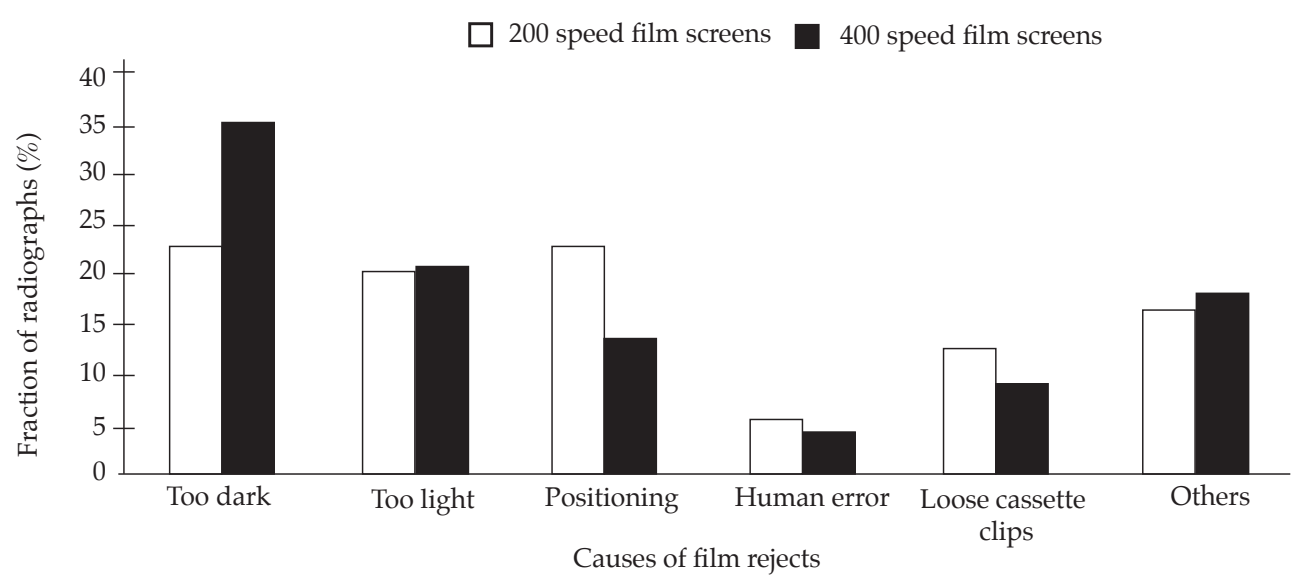

c) Exposure factors and quality control performance of the X-ray equipment

Table 1

The mean examination exposure factors used in each room for each film screen combinations

\begin{tabular}{|c|c|c|c|c|c|c|c|c|c|c|c|c|}
\hline \multirow[b]{3}{*}{ Organ/Site/ View } & \multicolumn{4}{|c|}{ Room 1} & \multicolumn{4}{|c|}{ Room 2} & \multicolumn{4}{|c|}{ Room 3} \\
\hline & \multicolumn{2}{|c|}{200 speed } & \multicolumn{2}{|c|}{400 speed } & \multicolumn{2}{|c|}{200 speed } & \multicolumn{2}{|c|}{400 speed } & \multicolumn{2}{|c|}{200 speed } & \multicolumn{2}{|c|}{400 speed } \\
\hline & $\mathrm{kVp}$ & $\mathrm{mAs}$ & $\mathrm{kVp}$ & mAs & $\mathrm{kVp}$ & mAs & $\mathrm{kVp}$ & mAs & $\mathrm{kVp}$ & $\mathrm{mAs}$ & $\mathrm{kVp}$ & $\mathrm{mAs}$ \\
\hline CXR PA & 70 & 18 & 63 & 4.12 & 70 & 17 & 68 & 4.25 & - & - & & - \\
\hline CXR AP & 68 & 5 & 52 & 2.17 & - & - & - & - & 55 & 3.2 & 58 & 0.8 \\
\hline PNS & - & - & - & - & & - & - & - & 60 & 6 & 62 & 1.2 \\
\hline Lumbar Spine AP & 81 & 72 & 73 & 21 & - & - & - & - & 62 & 19 & 62 & 4.75 \\
\hline Lumbar spine LAT & 90 & 80 & 80 & 26 & - & - & - & - & 66 & 17 & 66 & 4.25 \\
\hline Abdomen AP & 72 & 45 & 68 & 13 & 85 & 50 & 72 & 12.5 & - & - & - & - \\
\hline Pelvis AP & 72 & 40 & 70 & 10 & - & - & - & - & - & - & - & - \\
\hline
\end{tabular}

Dash (-) indicates examination not performed 
Table 1.2

$X$-ray performance tests results before and during the use of 400 speed film/screens combination

\begin{tabular}{|c|c|c|c|c|c|c|}
\hline \multirow[b]{2}{*}{ Quality control test } & \multicolumn{2}{|c|}{ Room 1} & \multicolumn{2}{|c|}{ Room 2} & \multicolumn{2}{|c|}{ Room 3} \\
\hline & Results & Comments & Results & Comments & Results & Comments \\
\hline $\mathrm{kVp}$ accuracy $( \pm 5 \%)^{*}$ & 1 & Pass & 3 & Pass & 2 & Pass \\
\hline Reproducibility of exposure $( \pm 2 \%)$ & 2 & Pass & 0.53 & Pass & $1^{*}$ & Pass \\
\hline Timer accuracy $( \pm 5 \%)$ & 1 & Pass & 1 & Pass & 1 & Pass \\
\hline $\mathrm{mA}$ and exposure time linearity $( \pm 10 \%)$ & 9 & Pass & 1 & Pass & 8 & Pass \\
\hline Radiation output $( \pm 5 \%)$ & 1 & Pass & 2 & Pass & 1 & Pass \\
\hline Light/radiation beam alignment ( $1 \%$ FID) & $1^{*}$ & Pass & 1.5 & Fail & 0.5 & Pass \\
\hline Focal spot size in $\mathrm{mm}(50 \% / 40 \%) \#$ & $2.2 / 2.2$ & Fail & $2.2 / 2.2$ & Fail & $2.2 / 2.2$ & Fail \\
\hline HVL (> $2.3 \mathrm{~mm} \mathrm{AI})$ & 4.4 & Pass & 3.5 & Pass & 3.7 & Pass \\
\hline
\end{tabular}

* test failed during the standard speed period. \# not corrected in both stages of the study. HVL measurements done at $80 \mathrm{kVp}$

d) The patient dose

Table 3

The mean ESD measurements, IAEA guidance levels $(8,9)$ in $m G y$ and dose reduction for all the rooms before and after the change to 400 speed film/screen systems

\begin{tabular}{|c|c|c|c|c|c|c|}
\hline & Examination type & $\begin{array}{l}200 \text { speed } \\
\text { ESD }\end{array}$ & $\begin{array}{l}\text { Guidance } \\
\text { level }\end{array}$ & $\begin{array}{l}400 \text { speed } \\
\text { ESD }\end{array}$ & $\begin{array}{l}\text { Guidance } \\
\text { level }\end{array}$ & $\begin{array}{l}\% \text { Dose } \\
\text { reduction }\end{array}$ \\
\hline \multirow[t]{7}{*}{ Adults } & CXR PA & $1.75 \pm 0.18$ & 0.4 & $0.41 \pm 0.04$ & 0.2 & 77 \\
\hline & $\mathrm{CXR} \mathrm{AP}^{\#}$ & $1.02 \pm 0.10$ & * & $0.34 \pm 0.03$ & * & 67 \\
\hline & CXR LAT & $3.34 \pm 0.33$ & 1.5 & $1.09 \pm 0.11$ & 0.75 & 67 \\
\hline & LUMBAR SPINE AP & $25.32 \pm 2.06$ & 10 & $7.07 \pm 0.71$ & 5 & 72 \\
\hline & LUMBAR SPINE LAT & $32.47 \pm 3.25$ & 30 & $8.54 \pm 0.85$ & 15 & 74 \\
\hline & ABDOMEN AP & $9.07 \pm 0.91$ & 10 & $2.87 \pm 0.29$ & 5 & 68 \\
\hline & PELVIS AP & $9.02 \pm 0.90$ & 10 & $2.55 \pm 0.26$ & 5 & 72 \\
\hline \multirow[t]{2}{*}{ Children* } & CXR AP & $0.36 \pm 0.04$ & * & $0.25 \pm 0.03$ & $0.050^{¥}$ & 31 \\
\hline & PNS & $0.79 \pm 0.08$ & * & $0.37 \pm 0.04$ & * & 53 \\
\hline
\end{tabular}

${ }^{*} \mathrm{GL}=$ not available. \#= None Grid $¥=$ National Radiation Protection Board (10) and European Commission (11)

Figure 3

The 200 and 400 speed image quality assessment results

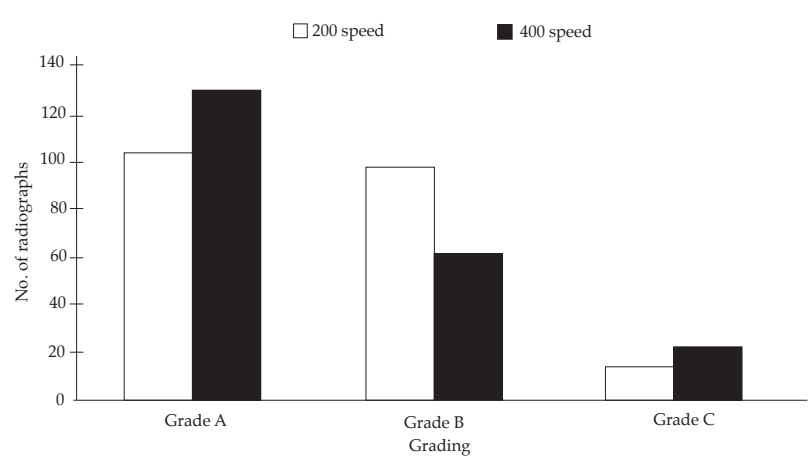

\section{DISCUSSION}

Examination frequencies: The distribution of the examinations in Figure 1 indicates a total of 355 adults and 82 children being considered in stage one while 482 and 147 patients were considered in stage two for the respective categories. The relative frequencies of radiographic examinations during both stages (corresponding 400 speed values are in brackets) was $44 \%$ (40\%) for chest, $20 \%$ (17\%) for lumbar spine, $5 \%$ in both stages for abdomen, $9 \%(7 \%)$ for pelvis respectively. The paediatric frequencies for chest and post nasal space (PNS) examination was 14\% (16\%) and $10 \%,(15 \%)$ respectively. The relative frequency calculated on the basis of the number of examinations and compared with the 1986 results reported by Tole 
(12) indicate an increase by a factor of two (chest) and three (lumbarspine and abdomen), respectively. These results agree with the values reported by the United Nations Scientific Committee on the Effects of Atomic Radiation (13). The increase may be attributed to lung infections, HIV / AIDS, motor accidents, chronic constipation, and intestinal obstruction.

For the paediatric examinations, both the chest and PNS constituted $24 \%$ (31\%) of all the radiological examinations. This frequency in the paediatric examinations may be attributed to chest, tonsillar and adenoidal infections. In general, the increased radiological examinations showed that there is a growing appreciation of the important role played by radiological examinations in patient diagnosis and management.

Rejects analysis: The results in Figure 2 illustrate the distribution of the relative frequencies and causes of films rejected at the technologist level. Too dark, too light, and positioning accounted for $67 \%$ before and $69 \%$ after the change of screen film systems. Prior to change (200 speed) rejects were accounted for as follows; too dark $24 \%$, toolight $20 \%$, positioning $23 \%$, The respective post change ( 400 speed) results were: $35 \%, 21 \%$ and $13 \%$, respectively. Post change rejects due to overexposure (too dark) increased significantly by $12 \%$, while those due to positioning decreased by $10 \%$. The results gave an insight into the occurrence attributed to the patient workload of $60 \%, 10 \%$, and $30 \%$ for rooms 1,2 and 3 , respectively, the difficulty in approximating the exposure factors from the observed patient size, an introduction of 400 speed film/screens combination without formulated exposure charts, and the training level of imaging technologists. Overall, pre and post change film rejects at this level were rated at $9 \%$ and $7 \%$ respectively. The major causes of film rejects contributed about two thirds of all the rejects in both stages. These findings are similar to those found by Mazzaferro et al (14). The film rejects due to other causes indicated in Figure 2 are image blur, improper collimation, processor failures, film storage and dark room errors. The $2 \%$ decrease in reject rates at the 400 speed stage was due to improved accuracy of exposure factors and the QC programme put in place. Routine comparison of reject analysis results, daily monitoring of processor performance, and plotting of the results, were recommended for use in initiating corrective actions.

Exposure factors and quality control performance of the X-ray equipment: Table 1 indicates the exposure factors employed for most examinations in each of the three rooms and reveals the underlying basic characteristic of radiation exposure to the patient and image receptor. The Tablealso illustrateshow low $\mathrm{kVp}$ technique was generally employed and reduced $\mathrm{mAs}$ values obtained after the change to 400 speed screen film combination. These changes are commensurate to patient dose optimization with the change of film screen, optimal device performance and selection of exposure factors. The use of high $\mathrm{kVp}$ technique leads to reduction in patient dose. The chest is the most frequently examined region and will have low photoelectric events resulting in high physiological contrast of lung and bones in the radiographs.

The equipment optimal performance in this study was rated as scoring of $75 \%$ and above on a total of eight equally weighted point scale system. The overall performance in Table 2 was $63 \%, 75 \%$, and $63 \%$ for rooms 1, 2, and 3 for the regular 200 speed stage. However, after correction of the machine performance failed tests (except the focal spot), the three equipments performed at $88 \%$ for the 400 speed stage.

The X-ray unit in room 3 failed the generator exposure reproducibility test. This outcome is an additional factor that contributed to high mean ESD values in Table 3. The X-ray unit in room 1 failed the proper mounting of the beam alignment housing test. This equipment failure occurred due to poor handling of the housing that is associated with high workload.

The consequences were unnecessarily high radiation exposure to the patients, image distortion, clipping of important anatomy, grid cut off and high film rejects due to positioning as revealed by the reject analysis. The baseline measurements and image blurs were not distinct, therefore further investigation was recommended to the medical physicist and QC technologist.

The patient dose: Table 3 shows the overall mean ESD values measured for eachexamination before and after the change to 400 speed film screen combination. The overall patient dose reduction was $75 \%$ for room 1 (12.9 mGy to $3.2 \mathrm{mGy}), 75 \%$ for room 2 (13.8 $\mathrm{mGy}$ to $3.4 \mathrm{mGy}$ ), and $46 \%$ for room 3 ( $0.6 \mathrm{mGy}$ to $0.3 \mathrm{mGy}$ ). None of the paediatric examinations complied with guidance levels but $67 \%$ of adult examinations were compliant in both stages.

A comparison with published data on dose to paediatric patients showed comparable dose of 0.27 $\mathrm{mGy}$ to chest AP even though it was measured using Dose Calsoftware (15). Interestingly, the potential for optimization was clearly evident for the $32 \%$ proportion of lumbar spine, abdomen and pelvis examinations which complied with the recommended guidance levels although it contributes the highest proportion of the collective patient dose.

The TLD card measuring method used in this study is known to have good sensitivity and has been proved by George, et al (16) while measuring adult dose was found to be in agreement with the semi empirical method used in most surveys $(11,16)$. However, the minimum radiation dose that can be 
measured with the TLD cards is $0.10 \mathrm{mGy}$. The lowest ESD measured was $0.13 \mathrm{mGy}$, therefore the TLD method offered the limitations observed in Table 3. Individual departments are recommended to use inbuilt Kerma Air Product (KAP) meters or semi empirical method for paediatric cases, in addition to routine dose assessment and management. These methods are suitable for diverse patient morphology, size, age, different film/screen combination, exposure techniques, equipment type and performance. During the study, theestimated body depths were determined as follows: $19 \mathrm{~cm}$ for adult chest PA/AP, chest LAT $26 \mathrm{~cm}$, lumbar spine AP $28 \mathrm{~cm}$, lumbar spine LAT $30 \mathrm{~cm}$, abdomen AP $21 \mathrm{~cm}$ and $17 \mathrm{~cm}$ for pelvis AP. The paediatric depths were $11 \mathrm{~cm}$ and $10 \mathrm{~cm}$ for chest $\mathrm{AP}$ and PNS respectively.

Image quality assessment: The results of the image quality assessment based on the European quality criteria are shown in Figure 3. At the regular 200 speed screen film combination, grade A was $48 \%$, B $45 \%$ and grade C $7 \%$. The respective values for 400 speed screen film combination stage was grade $\mathrm{A}$ at $61 \%$, grade B $29 \%$ and grade C $10 \%$. Between the two stages there was an improvement of $13 \%$ for grade $\mathrm{A}$ and a proportionate decrease of both grades B and C from $52 \%$ to $39 \%$. This is due to the significant difference in exposure factors between the two film screen combinations, slow implementation of QC tests of the processor and resistance associated with changes in the work environment. During the two stages, the film reject rates at this level were 8\% (200 speed) and 9\% (400 speed) respectively. These results were comparable with the technologists' level results for the first stage (9\%) but $2 \%$ less in the second stage. This difference reflects the effectiveness of accurate judicious exposure factors when using the 400 speed screen film combination with proportionate reduction in compliance with EC image quality criteria.

The rate of film reject at the radiologist level may not be consistent with film rejects at the technologist level. This assumption may have caused the wide range in the results reported by Muhogora et al (17). For equivalent referral hospitals, good approximation of thisquality factor using the proportion derived at the radiologist level alone can be obtained, by multiplying by two so as to accommodate rejects from the technologist level and representative of the department as a whole. During the study, the radiologists noted the requirement of quality clinical images and observed the effects and variation associated with each stage of the diagnostic image procedure.

\section{CONCLUSIONS AND RECOMMENDATIONS}

Patient dose is a combination of numerous factors. Performance of real patient dose measurements by individual hospitals is therefore important. It allows good understanding of exposure factors, working habits, and use of technological utilities, as well as sensitizing imaging professionals to the optimization of radiation protection and provision of effective $Q A$. The present study has established that optimization of patient dose in adults and paediatric patients can be improved by $31 \%$ and image quality improvement of $13 \%$ achieved.

The study found that direct radiography in paediatric examinations proved to require $X$ ray equipment with high generator capacity and appropriate dose assessment method. In addition the high film reject rate can be eliminated through use of effective QA/QC programme.

The use of guidance levels to meet the specific departmental quality needs is plausible irrespective of diverse imaging equipment and examination techniques. A complete structured feedback loop should ensure that all imaging professionals are sensitized on equipment performance and critical anatomical features during regular departmental quality review and audit.

\section{ACKNOWLEDGEMENTS}

To the Ministry of Health, management and radiology staff of Kenyatta National Hospital for accepting to participate in the IAEA project (RAF/9/033Strenthening Radiological Protection of Patient and Medical Exposure Control), the University of Nairobi, the National Council for Science and Technology and the International Atomic Energy Agency for their support.

\section{REFERENCES}

1. Kenya National Bureau of Statistics. Basic Report on Well Being in Kenya Based on Kenya Integrated Household Budget Survey-2005/2006, The Regal Press Kenya Limited, Nairobi. 96; 2007.

2. ICRP. International Commission on Radiological Protection, Recommendation of the International Commission on Radiological Protection. Oxford: Pergamon Press; ICRP Publication, Annals of the ICRP; 2005.

3. EC. European Commission, European Guidelines on Quality Criteria for Diagnostic Radiographic Images. EC Report 16260. EC, Luxembourg. 1996.

4. IAEA. International Atomic Energy Agency, International Basic Safety Standards for Protection against Ionizing Radiation and for the Safety of Radiation Sources. IAEASafety Series, No. 115; IAEA Vienna, 1996.

5. World Health Organization. A rational approach to radiodiagnosticinvestigations. Technical ReportSeries No. 689. WHO Geneva. 1983.

6. EPA. Environment Protection Authority, Registration requirements \& industry best practice for ionizing radiation apparatus used in diagnostic imaging. Radiation Guidelines; Test protocols for parts 2-5. Sydney. 2000 
7. IAEA. International Atomic Energy Agency, Dosimetry in Diagnostic Radiology: An International Code of Practice. Technical Reports Series No. 457 IAEA Vienna, 2007.

8. IAEA. International Atomic Energy Agency, Optimization of the radiological Protection of Patients Undergoing Radiotherapy, Fluoroscopy and Computed Tomography, IAEA, Vienna. 2004.

9. Rehani, M. M. Protection of patients in general radiography. International Atomic Energy Agency. Proceedings of the international conference 26-30 March 2001, Malaga. Vienna, Austria: International Atomic Energy Agency, 2001.

10. NRPB. National Radiation Protection Board. Guidelines on Patient Dose to Promote Optimization of Protection for Diagnostic Medical Exposures, 10: 1, NRPB Chilton, Didcot, UK. 1999.

11. EC. European Commission, Guidance on Diagnostic Reference Levels (DRLs) for Medical Exposures, Radiation Protection 109. EC, Luxembourg. 1999.

12. Tole, N.M. An estimate of the frequency of diagnostic X-ray examinations in Kenya in 1986. Bull. WId Hlth. Org. 1989; 67: 428.
13. UNSCEAR. United Nations Scientific Committee on the Effects of Atomic Radiation. Sources and efficts of ionizing radiation: report to the, General Assembly; annex, D medical radiation exposures. United Nations, New York. 2000.

14. Mazzaferro, J.R., MSEE, S.B. and Murray, L.J. The incidence and causes of repeated radiographic examinations in a community hospital. Radiology 1974; 112:71-72.

15. Suliman, I. I. and Elshiekh, E. H. A. Radiation doses from some Common Pediatric X-ray examinations in Sudan. Radiation Protection Dosimetry. 2008; 132: 1.

16. George, J., Eatough, J. P., Mountford, P. J., et al. Patient dose optimization in plain radiography based on standard exposure factors. Br. J. Radio. 2004; 77: 858863.

17. Muhogora, W.E., Ahmed, N. A. Almosabihi, A., et al. Patient doses in radiographic examinations in 12 countries in Asia, Africa, and Eastern Europe: Initial results from IAEA Projects. AJR. 2008; 190:14531461. 